\title{
Amazonian Biodiversity: A View of Drug Development for Leishmaniasis and Malaria
}

Leonardo de Azevedo Calderon, Izaltina Silva-Jardim, Juliana Pavan Zuliani, Alexandre de Almeida e Silva, Pietro Ciancaglini, Luiz Hildebrando Pereira da Silva and Rodrigo Guerino Stábeli*

$$
\text { 2009, vol. 20, No 6, 1011-1023. }
$$

Page $1014,4^{\text {th }}$ paragraph, $5^{\text {th }}$ sentence, the correct value is: $10 \mu \mathrm{g} \mathrm{mL}{ }^{-1}$.

Page $1015,1^{\text {st }}$ paragraph, $2^{\text {nd }}$ sentence, the correct value is: 25,50 , and $100 \mu \mathrm{gL}^{-1}$,

Page $1015,1^{\text {st }}$ paragraph, $3^{\text {rd }}$ sentence, the correct value is: $34.8 \mu \mathrm{mol} \mathrm{L} \mathrm{L}^{-1}$.

Page $1015,4^{\text {th }}$ paragraph, $5^{\text {th }}$ sentence, the correct value is: 5,15 , and $20 \mu \mathrm{gL}^{-1}$.

Page $1015,5^{\text {th }}$ paragraph, $7^{\text {th }}$ sentence, the correct value is: 0.5 and $24 \mu \mathrm{gL}^{-1}$. 